\title{
Research Article \\ Determination of Gossypol in Hamid and Bt (Seeni 1) Cottonseed Oil using Fourier Transform Infrared Spectroscopy
}

Samah A.M. Abdelrahman ${ }^{1}$
Atif A.A. Yassin ${ }^{1}$
Mohamed Elwathig Saeed
Mirghani 2*
Nabil H.H. Bashir ${ }^{3}$
1National Oilseed Processing Research
Institute (NOPRI), University of Gezira,
Medani, Al Jazirah State, Sudan
2International Institute for Halal
Research and Training (INHART),
International Islamic University
Malaysia, Gombak, Kuala Lumpur,
Malaysia
3Blue Nile National Institute for
Communicable Diseases, University of
Gezira, Medani, Al Jazirah State, Sudan
*email: elwathig@iium.edu.my
Keywords:
Bacillus thuringiensis
Cottonseed oil
FTIR spectroscopy
Gossypol
PLS

\begin{abstract}
This study was conducted to determine the gossypol content in $\mathrm{Bt}$ cottonseed (Seeni-1) oil by using Fourier Transform Infrared (FTIR) spectroscopy with an Attenuated Total Reflectance (ATR) element. The wavelengths used were selected by spiking refined, bleached deodorized palm oil (RBDPO) to gossypol concentrations of $0-5 \%$ and noting the regions of maximal absorbance. Absorbance values of the wavelength regions $3700-2400 \& 1900-750 \mathrm{~cm}^{-1}$ and a partial least squares (PLS) method were used to derive calibration models for Hamid cottonseed oil, Seeni-1 cottonseed oil, and gossypol-spiked RBDPO. The coefficients of determination $\left(R^{2}\right)$ for the calibration models were computed for the FTIR spectroscopy results against those found by using the wet chemical method AOCS method Ba 8-78. The $R^{2}$ was 0.8916 , 0.9581, and 0.9374 for Hamid cottonseed oil, Seeni- 1 cottonseed oil, and gossypol-spiked RBDPO, respectively. The standard error (SE) of the calibration was 0.053, 0.078, and 0.062, respectively. The calibration models were validated using the crossvalidation technique within the same set of oil samples. The results of FTIR spectroscopy as a useful technique determining gossypol content in crude cottonseed oil showed that there is a significant difference $(p$ $<0.05$ ) in the amount of gossypol content in Hamid and Bt Seeni-1 cottonseed oils.
\end{abstract}

Received: August 24th, 2020

Accepted: October 2nd, 2020

Published: November 30th 2020

(C) 2020 Samah A.M. Abdelrahman, Atif A.A. Yassin, Mohamed Elwathig Saeed Mirghani, Nabil H.H. Bashir. Published by Institute for Research and Community Services Universitas Muhammadiyah Palangkaraya. This is an Open Access article under the CC-BY-SA License (http://creativecommons.org/licenses/by-sa/4.0/). DOI: https://doi.org/10.33084/ bjop.v3i4.1592

\section{INTRODUCTION}

Gossypol (Gol) (Figure 1) is a toxic phenolic compound isolated since 1899 (Soto-Blanco, 2008). It is naturally produced by pigment glands, which are distributed in all parts of cotton (Gossypium spp.) plant (Gadelha et al., 2014; Wedegaertner \& Rathore, 2015), e.g., hulls, leaves, and stem, whereas gossypol is concentrated in the seed (Gadelha et al., 2014; Kenar, 2006; Rogers et al., 2002). The intense brownish-red color of crude oil refers to gossypol. Gossypol is the anti-nutritional compound secreted by the plant as an insect repellent, the glandless cotton being more susceptible to insect attack (Mirghani \& Che Man, 2003).<smiles>Cc1cc2c(C(C)C)c(O)c(O)c(C=O)c2c(O)c1-c1c(C)cc2c(C(C)C)c(O)c(O)c(C=O)c2c1O</smiles>

Figure 1. The chemical structure of gossypol 
The chemical formula of gossypol is $\mathrm{C}_{30} \mathrm{H}_{30} \mathrm{O}_{8}$; its chemical name is 2,2-bis(8-formyl-1,6,7-trihydroxy-5isopropyl-3-methyl naphthalene). Gossypol has a molecular weight of 518.55 Dalton, has a yellow pigment, crystalline, extremely yellow; insoluble in water and soluble in organic solvents and fats. Gossypol is partially soluble in crude vegetable oils (Soto-Blanco, 2008; Kenar, 2006). Its UV absorption maximum at about $385 \mathrm{~nm}(\varepsilon$ 18,000) solvent-dependent (Alexander et al., 2008). Gossypol is present in three tautomeric forms: gossypol allayed $\left(\mathrm{C}_{30} \mathrm{H}_{30} \mathrm{O}_{8}\right)$, gossypol lactol, and gossypol cyclic carbonyl (Soto-Blanco, 2008). Moreover, gossypol is a mixture of (-) and (+) enantiomers. The (-) isomer is the most biologically active form, hence, more toxic than $(+)$ isomer (Bailey et al., 2000; Kakani, 2010; Lordelo et al., 2005). The (+) gossypol is easily eliminated than the (-) form (Alexander et al., 2008).

The toxicokinetics studies showed two forms of gossypol, viz. free and bound (Wedegaertner \& Rathore, 2015). The bound form is produced via covalent bonds between gossypol and free epsilon amino groups from lysine and arginine (Soto-Blanco, 2008; Fernandez et al., 1995). Free gossypol is a physiologically active form, which is toxic to young ruminant animals than monogastric animals. The gossypol toxicity is moderate in most animal species (Alexander et al., 2008); for ruminant is less than for monogastric, since gossypol is bound to proteins in the rumen, i.e., unavailable for absorption. Free gossypol is lipophilic and readily absorbed by the intestine. Absorbed gossypol appears to have a long half-life in the body (Dalefield, 2017; SotoBlanco, 2008). Alexander et al. (2008) reported that gossypol influences the reproductive organ and growth of the embryo. Gossypol causes infertility, and in men, it stops spermatogenesis at low doses (Coutinho, 2002). Same toxicity and contraceptive to males were reported by Ye et al. (1983). Weather conditions and cotton species play a significant role in the production of total gossypol, e.g., positively correlated with rainfall rate and negatively correlated with temperature (Zhang et al., 2006).

Gossypium barbadense has high gossypol content than $G$. hirsutum. The level of gossypol declines slightly during cotton storage (Soto-Blanco, 2008). The concentration of total gossypol in cottonseed (CS) may be higher than $14,000 \mathrm{mg} / \mathrm{kg}$ and $7,000 \mathrm{mg} / \mathrm{kg}$ of free gossypol (Alexander et al., 2008). After oil extraction, the available concentration could be up to $0.6 \%$. However, in mechanical presser oil extracted and heat treatment, approximately $0.06 \%$ of gossypol could be available (Pons et al., 1953). Abdurakhim (2019) reported a study trying to control the content of gossypol using the biotechnological method by soaking the seed in biosolution that contains chicken droppings.

Bacillus thuringiensis (Bt) cotton is a genetically modified cotton that expresses an insecticidal protein (Kranthi, 2012). Bacillus thuringiensis produces insecticidal toxin protein (endotoxin) specific to lepidopteran insects. This bacteria were used in the traditional form of biopesticides or the modern form of genetically engineered (Ibrahim et al., 2010). Seeni- 1 is a Bt transgenic cotton variety released in 2012 by the National Variety Release Committee, Sudan, and approved by the Biosafety Authority for commercial production to control the bollworms. Crop protection costs ca. $30-40 \%$ of total cotton production cost. Fourier Transform Infrared (FTIR) spectroscopy is a method of an IR spectrometer, which measures an IR spectrum (Baker et al., 2014). Infrared passed across a sample, which absorbs some of the IR and some of it transmitted by the sample. The resulting spectrum represents the molecular absorption and transmission, creating a molecular fingerprint of the sample (Chen et al., 2015). Therefore, the IR spectra analysis can identify the unknown material, type, and concentration of molecules in the sample (Martens et al., 2018). An IR spectrum is 
formed because of the absorption of electromagnetic radiation that correlates to the vibration of specific sets of chemical bonds from within molecules. Therefore, Che Man \& Mirghani (2000) used FTIR to determine moisture- content and iodine value (IV) of palm oil. The determination of functional groups in coal was successfully done using FTIR spectroscopy (Painter et al., 1985). Hence, Mirghani \& Che Man (2003) reported that the FTIR spectroscopic technique is useful to substitute the standard wet chemical methods for gossypol's rapid and routine determination. This study's objective was to determine the gossypol concentration in Senni-1 oil and compare it to the gossypol in the traditional Sudanese cottonseed oil (CSO) by using the FTIR spectroscopy.

\section{MATERIALS AND METHODS}

\section{Materials}

The cottonseed oil samples, including Seeni-1, were obtained from the National Oilseed Processing Research Institute (NOPRI), University of Gezira, Sudan. All the reagents used were of analytical grade. Gossypol was purchased from Sigma Chemical Company, St. Louis, Missouri., US. Fifteen freshly refined CSO sets were prepared. The refined oil samples were spiked with gossypol over the range of $0 \sim 5 \%(0 \sim 50,000 \mathrm{ppm})$ standards calibration curve. The chemical analysis used to determine the gossypol - the content was that of the American Oil Chemists' Society (AOCS) method Ba 8-78 (Association of Official Analytical Chemists, 1995).

\section{Instrumental method}

The instrument used for analysis was a Nicolet iS50 FTIR spectrophotometer for (C) 2012 US Thermo Fisher Scientific Inc., using Nicolet Turbo Quant IR-Calibration and Prediction Package, Version 1.1 (Nicolet Instrument Co., Madison, Wisconsin). Samples were analyzed using FTIR spectrophotometer; spectral range $4000-600 \mathrm{~cm}^{-1}$. A deuterated triglycine sulfate (DTGS) detector, controlled by Nicolet Turbo Quant IR-Calibration and Prediction Package, installed in a PC. The instrument was purged with dry nitrogen and maintained with two automatic dehumidifiers to minimize $\mathrm{CO}_{2}$ and water vapor interference. Melted drops of each standard placed on top of the attenuated total reflectance (ATR) element. The ATR element's tipping point was rinsed three times with acetone and then dried with soft tissue before the introduction of the next sample. Calibration spectra were collected by 16 scans of each of the sample and the standard, at a resolution of $1 \mathrm{~cm}^{-1}$, a gain of 1.0 , and strong apodization throughout the mid-IR region of 4000-600 $\mathrm{cm}^{-1}$. The spectra were ratioed against the background air spectrum. All the samples were scanned in triplicates, with the spectra recorded as absorbance and/or transmittance at each data point. The absorbance spectra were stored on a disk as SPA format files for subsequent chemometric analysis (Alkhalf \& Mirghani, 2017).

\section{Statistical analysis}

The relationships between each of the parameters obtained by the FTIR spectrum and standard chemical method were determined using the software Nicolet Turbo Quant IR-Calibration and Prediction Package, Version 1.1. A partial least squares (PLS) regression statistical approach was developed for the mathematical treatment of the FTIR predicted data using this software. The data transferred to Microsoft Excel 2016 spreadsheets to derive regressions between the FTIR-PLS predicted and chemical analysis data. The similarity between the chemical data and PLS predictions of gossypol-content for the samples used in the calibration indicated the PLS model's adequacy. The PLS model's accuracy was assessed based on the SE and the highest coefficient of determination $\left(R^{2}\right)$ (Mirghani \& Che Man, 2003).

\section{Validation}

The set of standards used for cross-validation method leaving out one sample at a time. Given the set of 15 
calibration spectra, the PLS calibration on 14 calibration spectra was performed, and the concentration of the sample left out during calibration was predicted using this calibration. This process was repeated until each sample had left for once. The concentration of each sample was then predicted and compared with the known concentration of this reference sample. The accuracy was assessed by the SE of cross-validation (SECV) and $R^{2}$. Further, cross-validation results were employed to compute the mean difference (MD), and a standard deviation of difference (SDD) for repeatability and accuracy between the chemical and FTIR predicted the gossypol-contents.

\section{RESULTS AND DISCUSSION}

The results obtained from chemical and FTIR analyses as means with standard deviation $(\mathrm{SD})$ and relative $\mathrm{SD}(\mathrm{CV})$ for total gossypol contents in the calibration sets of cottonseed oil, Bt CSO, and gossypol-spiked CSO samples are shown in Table I. With the AOCS method (Association of Official Analytical Chemists, 1995), the mean gossypol-contents were $0.47,0.39$, and $2.15 \%$, respectively. The FTIR spectroscopic analysis gave the corresponding values of $0.52,0.41$, and $2.64 \%$. The CV values are relatively high (poor precision) for the low gossypol-content by both the chemical AOCS and FTIR methods. However, the result still acceptable within this range of $\mathrm{CV}$ values.

Table I. Gossypol contents determined by the AOCS wet chemical method and FTIR spectroscopy method

\begin{tabular}{|c|c|c|c|c|c|c|}
\hline \multirow{2}{*}{$\begin{array}{c}\text { CSO } \\
\text { Sample }\end{array}$} & \multicolumn{3}{|c|}{ AOCS } & \multicolumn{3}{|c|}{ FTIR } \\
\hline & $\begin{array}{c}\text { Mean } \\
(\%)\end{array}$ & $\begin{array}{l}( \pm) \\
\text { SD }\end{array}$ & $\mathrm{CV} \%$ & $\begin{array}{c}\text { Mean } \\
(\%)\end{array}$ & $\begin{array}{l}( \pm) \\
\text { SD }\end{array}$ & $\mathrm{CV} \%$ \\
\hline $\begin{array}{l}\text { Hamid } \\
\text { CSO }\end{array}$ & $0.47^{a}$ & 0.051 & 08.06 & $0.52^{a}$ & 0.064 & 08.85 \\
\hline $\begin{array}{l}\text { Seeni-1 } \\
\text { CSO }\end{array}$ & $0.39^{b}$ & 0.026 & 10.20 & $0.41^{b}$ & 0.027 & 11.24 \\
\hline $\begin{array}{l}\text { Gossypol- } \\
\text { spiked } \\
\text { RBDPO }\end{array}$ & $2.15^{c}$ & 0.094 & 06.22 & $2.64^{c}$ & 0.075 & 05.16 \\
\hline
\end{tabular}

$\overline{\mathrm{SD}}=$ Standard deviation; $\mathrm{CSO}=$ cottonseed oil; $\mathrm{RBDPO}=$ Refined bleached deodorized palm oil.

Different subscripts letter in the column and rows are significantly different $(p<0.05)$

\section{Spectra}

Figure 2 shows the spectrum of gossypol in the frequency range of $4000-650 \mathrm{~cm}^{-1}$. A band at $3375 \mathrm{~cm}^{-1}$ for $-\mathrm{OH}$ is associated with phenol, and bands at $3004 \mathrm{~cm}^{-}$ ${ }^{1}$ are for unsaturation $-\mathrm{C}=\mathrm{C}-$ and isomerization. Bands at 2970 and $2911 \mathrm{~cm}^{-1}$ were assigned as unsaturated and aromatic (phenyl) - $\mathrm{CH}$ vibrations, respectively. The bands at 2362, 1737, 1719, and $1440 \mathrm{~cm}^{-1}$ are due to aromatic aldehydes, phenyl ring stretching, $-\mathrm{C}-\mathrm{OH}$ inplane bending, aromatic $\mathrm{C}=\mathrm{C}$, and methyl bending vibration (Mirghani et al., 2011). The bands at 1364, 1228, and $1218 \mathrm{~cm}^{-1}$ are assigned for in-plane $-\mathrm{CH}$ of substituted phenyl. The sharp bands at 1093, 1055, 903, and $845 \mathrm{~cm}^{-1}$ are assigned to the in-plane $-\mathrm{CH}$ bending of phenyl, phenolic - $\mathrm{OH}$, two adjacent phenyls, and the band $845 \mathrm{~cm}^{-1}$ is for the $-\mathrm{CH}$ of p-di-substituted phenyl. The band at $772 \mathrm{~cm}^{-1}$ to $-\mathrm{CH}$ out-of-plane bending (Yadav, 2005; Stuart, 2004). Figure 3 showed the spectrum of cottonseed oil-spiked gossypol that has might bands as in vegetable oils in addition to some other bands of gossypol; however, challenging to differentiate using the naked eye. Figure 4 shows the spectra of both types of CSOs, conventional and Bt CSOs. Both spectra look normal like other vegetable oils; however, the fast Fourier transform algorithm Cooley \& Tukey (CooleyTukey FFT algorithm) (Arrondo et al., 1993) as part of the software with FTIR instrument was used to determine and quantify the amount of gossypol in both oil samples.

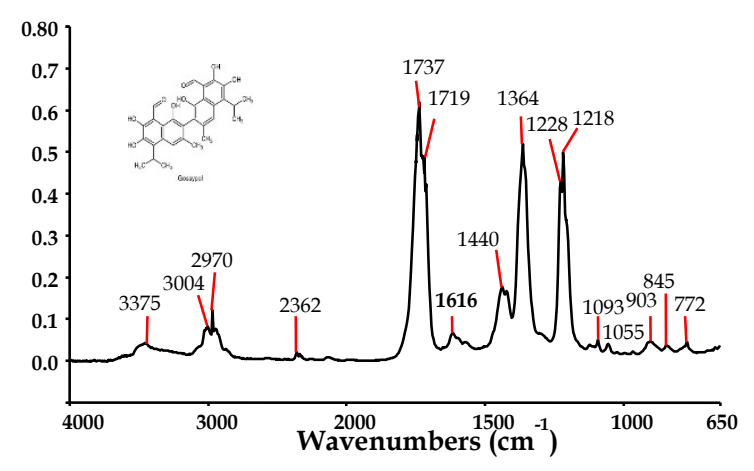

Figure 2. FTIR spectrum of gossypol 


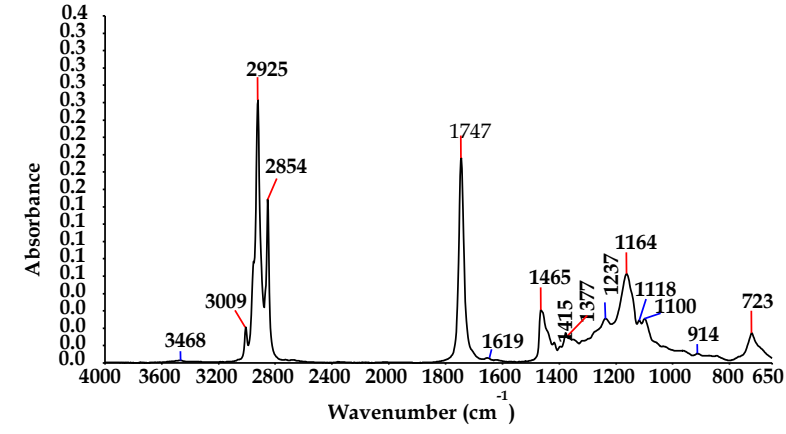

Figure 3. FTIR spectrum of cottonseed-spiked with gossypol

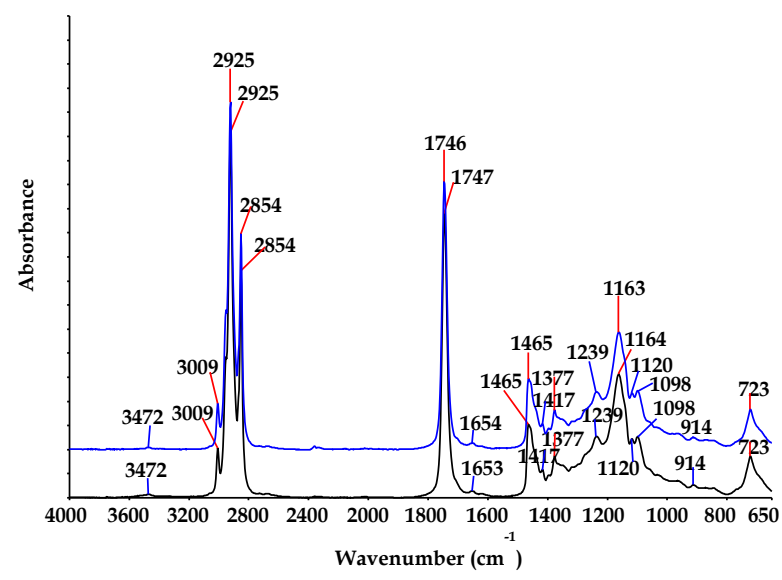

Figure 4. The spectra of Hamid cottonseed oil and Bt (Seeni-1) cottonseed oil

\section{Development of calibration models}

The best spectral region for gossypol determination was selected using variance and correlation spectra. The data from the selected regions with features of interest related to gossypol were abstracted by the PLS software for the calibration standards. The chemical analysis results to be uniquely representative of the samples to be analyzed (Fuller et al.,1988). The spectral regions that show the best correlation between the gossypol content and spectral response were set and selected to include all the data from $3700-2400 \mathrm{~cm}^{-1}$ and from $1900-750 \mathrm{~cm}^{-1}$ for determining the gossypol content in the cottonseed oil and Bt cottonseed oil samples as presented in Table II. The data from these regions produced the highest $R^{2}$ and lowest SE of calibration and SECV for calibration and cross-validation.
Table II. Calibration and cross-validation using PLS regression for the data of the wavenumber regions $3700-2400 \mathrm{~cm}^{-1}$ and $1900-750 \mathrm{~cm}^{-1}$ for gossypol content

\begin{tabular}{lcccc}
\hline \multirow{2}{*}{ CSO Sample* } & \multicolumn{2}{c}{ Calibration } & \multicolumn{2}{c}{ Validation } \\
\cline { 2 - 5 } & $R^{2}$ & SEC & $R^{2}$ & SECV \\
\hline Hamid & 0.8916 & 0.053 & 0.8936 & 0.064 \\
Seeni-1 & 0.9581 & 0.078 & 0.9205 & 0.091 \\
Gossypol-spiked & 0.9374 & 0.062 & - & - \\
RBDPO $^{*}$ & & & & \\
\hline
\end{tabular}

$R^{2}=$ coefficient of determination; $\mathrm{SEC}=$ standard error of calibration; $\mathrm{SECV}=$ standard error of cross-validation

* See Table I

A regression was derived by plotting the gossypol contents in the Seeni-1 CSO as determined by the AOCS method against the calibration set (Figure 5). The equation of $y=0.8182 x+0.2625\left(R^{2}=0.9581\right)$ had an intercept and slope not significantly different $(p>0.05)$ from 0.0 and 1.0, respectively. The calibration evaluated by cross-validation, and Figure 6 shows the validation of the predictive model with the actual gossypol contents compared with the data obtained by the FTIR spectroscopy. The plot was linear and $R^{2}$ of 0.9205 . The SECV was 0.091, indicating that the method's accuracy was good, reflecting that the statistically predicted gossypol contents were very close to the actual values. In conclusion, FTIR spectroscopy was a potential analytical tool for the simple and rapid quantitative determination of gossypol in Seeni-1 CSO.

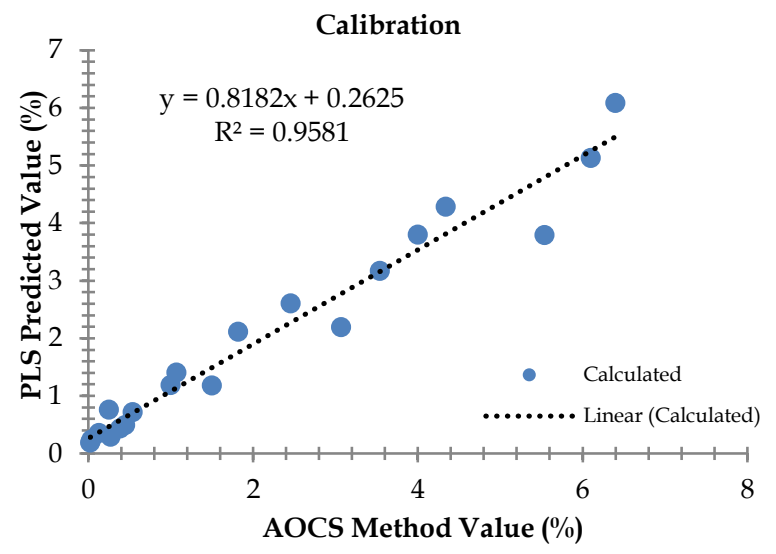

Figure 5. Plot of gossypol content in Bt (Seeni-1) cottonseed oil by AOCS chemical method vs. PLS-predicted values for calibration 


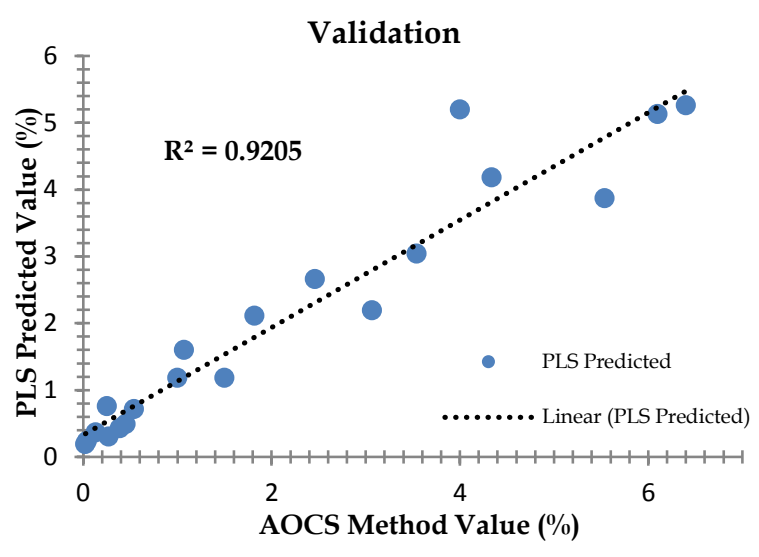

Figure 6. Plot of gossypol content in Bt (Seeni-1) cottonseed oil by AOCS chemical method vs. PLS-predicted values for validation

\section{CONCLUSION}

FTIR spectroscopy with an ATR element was successfully used to determine the gossypol content in the newly introduced Bt cottonseed (Seeni-1) verity. Absorbance values from the wavelength regions 37002400 and $1900-750 \mathrm{~cm}^{-1}$ and a PLS method were used to derive calibration models. Three types of oils were used to confirm the calibration; Hamid cottonseed oil, Seeni-1 cottonseed oil, and gossypol-spiked RBDPO. The coefficients of determination $\left(R^{2}\right)$ for the calibration models were computed for the FTIR spectroscopy results against those found by the wet chemical method. The $R^{2}$ was 0.8916; 0.9581; and 0.9374 for Hamid cottonseed oil, Seeni-1 cottonseed oil, and gossypol-spiked RBDPO, respectively. The SE of the calibration was $0.053 ; 0.078$; and 0.062 , respectively. The final validated results of FTIR spectroscopy as a useful technique for the determination of gossypol content in crude cottonseed oil showed that there is a significant difference $(p<0.05)$ in the amount of gossypol content in Hamid and Bt (Seeni-1) cottonseed oils.

\section{ACKNOWLEDGMENT}

The authors thank the International Institute for Halal Research and Training (INHART), and Kulliyyah of
Engineering, International Islamic University Malaysia (IIUM), for allowing to use of the facilities and laboratories for this study. The first author is grateful to the National Oilseed Processing Research Institute (NOPRI), University of Gezira, Sudan, for allowing the chance for such a student mobility program.

\section{REFERENCES}

Abdurakhim, K. (2019). Biotechnological Method of Controlling the Content of Gossypol and Its Value. European Science Review, 1(1-2), 3-5.

Alexander, J., Benford, D., Cockburn, A., Cravedi, J.P., Dogliotti, E., Di Domenico, A., FérnandezCruz, M.L., Fürst, P., Fink-Gremmels, J., Galli, C.L., Grandjean, P., Gzyl, J., Heinemeyer, G., Johansson, N., Mutti, A., Schlatter, J., van Leeuwen, R., Van Peteghem, C., \& Verger, P. (2008). Gossypol as undesirable substance in animal feed. EFSA Journal, 908, 1-55.

Alkhalf, M.I. \& Mirghani, M.E.S. (2017). Detection of formaldehyde in cheese using FTIR spectroscopy. International Food Research Journal, 24(Suppl), S496-S500.

Arrondo, J.L., Muga, A., Castresana, J., \& Goñi, F.M. (1993). Quantitative studies of the structure of proteins in solution by Fourier-transform infrared spectroscopy. Progress in Biophysics and Molecular Biology, 59(1), 23-56. doi:10.1016/0079-6107(93)90006-6

Association of Official Analytical Chemists. (1995). Official Methods of Analysis Ba 8-78. Maryland, US: Association of Official Analytical Chemists.

Bailey, C.A., Stipanovic, R.D., Ziehr, M.S., Haq, A.U., Sattar, M., Kubena, L.F., Kim, H.L., \& Vieira, R.M. (2000). Cottonseed with a High (+)- to (-)Gossypol Enantiomer Ratio Favorable to Broiler Production. Journal of Agricultural and Food Chemistry, 48(11), 5692-5695. doi:10.1021/jf000211n

Baker, M.J., Trevisan, J., Bassan, P., Bhargava, R., Butler, H.J., Dorling, K.M., Fielden, P.R., Fogarty, S.W., Fullwood, N.J., Heys, K.A., Hughes, C., Lasch, P., Martin-Hirsch, P.L., Obinaju, B., Sockalingum, G.D., Sulé-Suso, J., Strong, R.J., 
Walsh, M.J., Wood, B.R., Gardner, P., \& Martin, F.L. (2014). Using Fourier transform IR spectroscopy to analyze biological materials. Nature Protocols, 9(8), 1771-1791. doi:10.1038/nprot.2014.110

Che Man, Y.B. \& Mirghani, M.E.S. (2000). Rapid method for determining moisture content in crude palm oil by Fourier transform infrared spectroscopy. Journal of the American Oil Chemists' Society, 77(6), 631-637. doi:10.1007/s11746-000-0102-9

Chen, Y., Zou, C., Mastalerz, M., Hu, S., Gasaway, C., \& Tao, X. (2015). Applications of Micro-Fourier Transform Infrared Spectroscopy (FTIR) in the Geological Sciences-A Review. International Journal of Molecular Sciences, 16(12), 3022330250. doi:10.3390/ijms161226227

Coutinho, E.M. (2002). Gossypol: a contraceptive for men. Contraception, 65(4), 259-263. doi:10.1016/S0010-7824(02)00294-9

Dalefield, R. (2017). Veterinary Toxicology for Australia and New Zealand, $1^{\text {st }}$ Edition. Amsterdam, Netherlands: Elsevier.

Fernandez, S.R., Zhang, Y., \& Parsons, C.M. (1995). Dietary formulation with cottonseed meal on a total amino acid versus a digestible amino acid basis. Poultry Science, 74(7), 1168-1179. doi:10.3382/ps.0741168

Fuller, M.P., Ritter, G.L., \& Draper, C.S. (1988). Partial Least-Squares Quantitative Analysis of Infrared Spectroscopic Data. Part II: Application to Detergent Analysis. Applied Spectroscopy, 42(2), 228-236. doi:10.1366/0003702884428347

Gadelha, I.C.N., Fonseca, N.B.S., Oloris, S.C.S., Melo, M.M., \& Soto-Blanco, B. (2014). Gossypol Toxicity from Cottonseed Products. The Scientific World Journal, 2014, 231635. doi:10.1155/2014/231635

Ibrahim, M.A., Griko, N., Junker, M., \& Bulla, L.A. (2010). Bacillus thuringiensis: $A$ genomics and proteomics perspective. Bioengineered Bugs, 1(1), 31-50. doi:10.4161/bbug.1.1.10519

Kakani, R., Gamboa, D.A., Calhoun, M.C., Haq, A.U., \& Bailey, C.A. (2010). Relative Toxicity of Cottonseed Gossypol Enantiomers in Broilers.
The Open Toxicology Journal, 4, 26-31. doi:10.2174/1874340401004010026

Kenar, J.A. (2006). Reaction chemistry of gossypol and its derivatives. Journal of the American Oil Chemists' Society, 83(4), 269-302. doi:10.1007/s11746-0061203-1

Kranthi, K.R. (2012). Bt Cotton: Questions and Answers. Mumbai, India: Indian Society for Cotton Improvement.

Lordelo, M.M., Davis, A.J., Calhoun, M.C., Dowd, M.K., \& Dale, N.M. (2005). Relative toxicity of gossypol enantiomers in broilers. Poultry Science, $\quad 84(9), \quad$ 1376-1382. doi:10.1093/ps/84.9.1376

Martens, J., Berden, G., Bentlage, H., Coene, K.L.M., Engelke, U.F., Wishart, D., van Scherpenzeel, M., Kluijtmans, L.A.J., Wevers, R.A., \& Oomens, J. (2018). Unraveling the unknown areas of the human metabolome: the role of infrared ion spectroscopy. Journal of Inherited Metabolic Disease, 41(3), 367-377. doi:10.1007/s10545-018-0161-8

Mirghani, M.E.S., Kabbashi, N.A., Alam, M.Z., Qudsieh, I.Y., \& Alkatib, M.F.R. (2011). Rapid Method for the Determination of Moisture Content in Biodiesel Using FTIR Spectroscopy. Journal of the American Oil Chemists' Society, 88(12), 18971904. doi:10.1007/s11746-011-1866-0

Mirghani, M.E.S. \& Che Man, Y.B. (2003). A new method for determining gossypol in cottonseed oil by FTIR spectroscopy. Journal of the American Oil Chemists' Society, 80(7), 625-628. doi:10.1007/s11746-003-0749-2

Painter, P., Starsinic, M., \& Coleman, M. (1985). Determination of Functional Groups in Coal by Fourier Transform Interferometry. In Ferraro, J.R. \& Basile, L.J. (Eds). Fourier Transform Infrared Spectra: Applications to Chemical Systems, 4, 169-241. Cambridge, US: Academic Press.

Pons, W.A., Hoffpauir, C.L., \& Hopper, T.H. (1953). Gossypol in cottonseed: influence of variety of cottonseed and environment. Journal of Agricultural and Food Chemistry, 1(18), 11151118.

Rogers, G.M., Poore, M.H., \& Paschal, J.C. (2002). Feeding cotton products to cattle. Veterinary Clinics of 
North America: Food Animal Practice, 18(2), 267294. doi:10.1016/s0749-0720(02)00020-8

Soto-Blanco, B. (2008). Gossipol e fatores antinutricionais da soja. In Spinosa, H.S., Górniak, S.L., \& Neto, J.P. (Eds.), Toxicologia Aplicada à Medicina Veterinária, 531-545. Barueri, Brazil: Manole.

Stuart, B.H. (2004). Infrared Spectroscopy: Fundamentals and Applications. New Jersey, US: John Wiley \& Sons. doi:10.1002/0470011149.ch3

Wedegaertner, T. \& Rathore, K. (2015). Elimination of Gossypol in Cottonseed will Improve its Utilization. Procedia Environmental Sciences, 29, 124-125. doi:10.1016/j.proenv.2015.07.212

Yadav, L.D.S. (2005). Organic Spectroscopy. 52-106. Dordrecht, Netherlands: Springer.

Ye, W.S., Liang, J.C., \& Hsu, T.C. (1983). Toxicity of a male contraceptive, gossypol, in mammalian cell cultures. In Vitro, 19(1), 53-57. doi:10.1007/bf02617994

Zhang, W.J., Xu, Z.R., Sun, J.Y., \& Yang, X. (2006). Effect of selected fungi on the reduction of gossypol levels and nutritional value during solid substrate fermentation of cottonseed meal. Journal of Zhejiang University SCIENCE B, 7(9), 690-695. doi:10.1631/jzus.2006.B0690 